\title{
Design equations for complementary electrochromic devices: application to the tungsten oxide-Prussian blue system
}

\author{
Lin-Chi Chen, Kuo-Chuan Ho * \\ Department of Chemical Engineering, National Taiwan University, Taipei 10617, Taiwan
}

Received 21 August 2000; received in revised form 7 November 2000

\begin{abstract}
Complementary electrochromic devices (ECDs) have advantages in offering deeper switching over singer-layer ECDs. Therefore, it is important to gain an insight into the dominant factors that control the electrochromic performance of complementary ECDs. In this study, the design of complementary ECDs with two reversible redox electrodes operating in series is presented. By combining the electrochemical and optical properties of these two electrodes, design equations suitable for complementary ECDs are derived. As the overall extent of electrochromic reaction involved in an ECD is limited by the electrode with a lower charge capacity, the effect of charge capacity ratio on the optical attenuation range can be predicted. The required parameters in the design equations are evaluated from the fabricated cell. As an example, the tungsten oxide-Prussian blue system is discussed. The empirical prediction of the optical attenuation range is fitted well with the experimental results. () 2001 Elsevier Science Ltd. All rights reserved.
\end{abstract}

Keywords: Charge capacity; Electrochromic; Optical attenuation; Prussian blue; Tungsten trioxide

\section{Nomenclature}

$A$

$k$

$Q$

$q$

$R$

$T$

Greek letters

$\alpha_{i}^{\prime}$

$\delta$

$\Delta \mathrm{OD}$ active electrode area $\left(\mathrm{cm}^{2}\right)$ proportionality constant defined in Eq. (10) $\left(\mathrm{C} / \mathrm{cm}^{3}\right)$ charge injected/extracted (C) charge injected/extracted per unit electrode area $\left(\mathrm{C} / \mathrm{cm}^{2}\right)$ charge capacity ratio (dimensionless) transmittance (\%)

attenuation coefficient $\left(\mathrm{cm}^{-1}\right)$ defined in Eq. (12) $\left(\mathrm{cm}^{2} / \mathrm{C}\right)$

film thickness $(\mathrm{cm})$ optical density change (dimensionless)

* Corresponding author. Fax: + 886-2-2362-3040. E-mail address: kcho@ms.cc.ntu.edu.tw (K.-C. Ho).
$\Delta T$

$\phi$

$\eta(\lambda)$

$\eta_{i}^{\prime}$

$\lambda$

Superscripts 0 b calc d $\mathrm{m}$ res rxn

Subscripts 550 transmittance window $(\%)$

combined transmittance accounting for the presence of both transparent conducting substrate and electrolyte (dimensionless) coloration efficiency $\left(\mathrm{cm}^{2} / \mathrm{C}\right)$ defined in Eq. (8) $\left(\mathrm{cm}^{2} / \mathrm{C}\right)$ wavelength $(\mathrm{nm})$

initial state bleached state calculated value darkened state maximum value residual value reacted value measurement performed at $\lambda=550$ $\mathrm{nm}$ 


$\begin{array}{ll}\mathrm{c} & \text { counter-electrode } \\ \mathrm{ECD} & \text { electrochromic device } \\ \mathrm{i} & \text { ith electrochromic layer } \\ \mathrm{p} & \text { Prussian blue (or working electrode) } \\ \mathrm{w} & \text { tungsten oxide }\end{array}$

\section{Introduction}

A complementary electrochromic device is essentially a transparent electrochemical battery which consists of three major components: (1) electrochromic working electrode, (2) electrochromic counter-electrode, and (3) electrolyte. Such electrochromic devices exhibit reversibly adjustable light transmittance induced by an applied, low-voltage dc electrical current. In fact, $\mathrm{WO}_{3}$ is probably the most investigated material among various electrochromic materials [1]. Despite extensive research efforts so far, there are several problems that still need to be overcome before the realization of the device. These include the need for an electrochemically reversible, charge balanced counter-electrode and a thermally, as well as electrochemically, stable electrolyte over a wide temperature range.

\subsection{Complementary electrochromic systems}

Among various electrochromic materials, tungsten oxide has been investigated by many researchers and is thought to be one of the best choices for the primary working electrode material. A complementary counterelectrode colors and bleaches in phase with the working electrode during oxidation-reduction cycling. Complementary materials to tungsten oxide include $\mathrm{IrO}_{2}$, nickel hydroxide, polyaniline and its derivatives, Prussian blue (PB), etc. When an adequate voltage is applied between $\mathrm{WO}_{3}$ and one of these complementary electrodes, such that the $\mathrm{WO}_{3}$ electrode is the cathode and the complementary electrode is the anode, both films color simultaneously. This is because $\mathrm{WO}_{3}$ is a cathodically coloring material and its complementary counterpart an anodically coloring one.

\subsection{Electrochromism for $\mathrm{WO}_{3}$ and $\mathrm{PB}$}

It is understood that $\mathrm{PB}$ resembles certain transition metal oxides, such as $\mathrm{WO}_{3}$, which have been called insertion compounds. In the case of PB as the counterelectrode, the generally accepted electrochromic switching principles are as follows:

$$
\begin{aligned}
& \mathrm{M}_{x} \mathrm{WO}_{3} \text { (blue) } \rightleftharpoons \mathrm{WO}_{3} \text { (colorless) }+x \mathrm{M}^{+}+x \mathrm{e}^{-} \\
& \left.\mathrm{Fe}_{4}^{\mathrm{III}}\left[\mathrm{Fe}^{\mathrm{II}}(\mathrm{CN})_{6}\right]_{3} \text { (blue }\right)+4 \mathrm{M}^{+}+4 \mathrm{e}^{-} \\
& \rightleftharpoons \mathrm{M}_{4} \mathrm{Fe}_{4}^{\mathrm{II}}\left[\mathrm{Fe}^{\mathrm{II}}(\mathrm{CN})_{6}\right]_{3} \text { (colorless) }
\end{aligned}
$$

where $\mathrm{M}^{+}$can be $\mathrm{Li}^{+}, \mathrm{Na}^{+}$or $\mathrm{K}^{+}$. Itaya et al. [2] among others reported that $\mathrm{K}^{+}$is the best of these as a counter ion for PB in aqueous electrolytes because of the small radius of its hydrated ion. While $\mathrm{PB}$ is an interesting counter-electrode material, it is generally known for its incompatibility with liquid proton-conducting electrolytes [3,4]. Proton hydration is believed to cause the incompatibility. Presumably, this is due to hindrance by the attached $\mathrm{H}_{2} \mathrm{O}$ in the zeolitic $\mathrm{PB}$.

\subsection{Coloration efficiency}

One of the most important criteria in selecting an electrochromic material is its coloration efficiency. The coloration efficiency of the electrochromic material $i$, $\eta_{i}(\lambda)$, is defined as the change in optical density (at a particular wavelength) per unit of injected charge density, or

$\eta_{i}(\lambda) \equiv\left[\frac{\Delta \mathrm{OD}(\lambda)}{Q / A}\right]_{i}=\left[\frac{\log \left(T^{\mathrm{b}} / T^{\mathrm{d}}\right)}{q}\right]_{i}$

where $\Delta \mathrm{OD}(\lambda)$ is the optical density change measured at wavelength $\lambda, Q$ the amount of charge injected/extracted, $A$ the active electrode area, $T^{\mathrm{b}}$ and $T^{\mathrm{d}}$ the transmittances at $\lambda$ in the bleached and darkened state, respectively, and $q$ the charge injected/extracted per unit electrode area. It can be shown that the overall coloration efficiency of a complementary electrochromic system, $\eta(\lambda)$, is the sum of the coloration efficiencies of the individual coloring films. That is, the overall coloration efficiency is the sum of the coloration efficiency of the working electrode and that of the counter-electrode, or

$\eta(\lambda) \equiv \eta_{\mathrm{w}}(\lambda)+\eta_{\mathrm{c}}(\lambda)=\left[\frac{\Delta \mathrm{OD}(\lambda)}{Q / A}\right]_{\mathrm{w}}+\left[\frac{\Delta \mathrm{OD}(\lambda)}{Q / A}\right]_{\mathrm{c}}$

A partial list of complementary ECDs containing the $\mathrm{WO}_{3}-\mathrm{PB}$ couple explored during the past two decades is summarized in Table 1, including transmittance values for each system where known.

It is noted, from Table 1, that complementary electrochromic devices made with the $\mathrm{WO}_{3}-\mathrm{PB}$ couple, when in conjunction with a $\mathrm{Li}^{+}, \mathrm{K}^{+}$, or $\mathrm{H}^{+}$-conducting electrolyte, are generally known to have low bleached state transmittance. Among all ECDs summarized in Table 1, Kase et al. [14,15] reported a device based on the $\mathrm{WO}_{3}-\mathrm{PB}$ couple by using a $1 \mathrm{M} \mathrm{LiClO}_{4}$ in propylene carbonate with $1-2 \% \mathrm{H}_{2} \mathrm{O}$ as the electrolyte. Typical luminous transmittances in the darkened state were $5-10 \%$ while those of the bleached state were $50-70 \%$. However, the variation of the transmittances, both in the darkened and the bleached states, is unclear. Although many researchers have reported about the transmittance range for prospective configurations, as shown in Table 1, nevertheless, very little information about the theoretical modeling for the transmittance is available for analysis. 
In an earlier report [17], we found that the variation of the transmittance range depends both on the size of the sample and on the charge capacity ratio on two electrodes. In the present study, as a means of enhancing the proton compatibility with $\mathrm{PB}$ electrode and of varying the charge capacity ratio on two electrodes, $\mathrm{H}_{x} \mathrm{WO}_{3}$ /proton-conducting solid polymer electrolyte $\left(\mathrm{H}^{+}\right.$-SPE)/PB complementary cells were made. This electrochromic transparency configuration, of electrically conductive glass $/ \mathrm{H}_{x} \mathrm{WO}_{3} / \mathrm{H}^{+}-\mathrm{SPE} / \mathrm{PB} /$ electrically conductive glass, hereafter referred to as $\mathrm{H}_{x} \mathrm{WO}_{3} / \mathrm{H}^{+}$. $\mathrm{SPE} / \mathrm{PB}$, is based on the complementary electrochemistry of Eqs. (1) and (2) with $\mathrm{M}^{+}$being $\mathrm{H}^{+}$. It is shown, both theoretically and experimentally, that the key to approaching the optimal transmittance attenuation lies in the ability to maintain balanced charge capacity between the working and the counter-electrodes. That is, the best performing complementary electrochromic device possesses nearly ideally matched charge capacities.

Table 1

Examples of complementary ECDs containing the $\mathrm{WO}_{3}-\mathrm{PB}$ couple $^{\text {a }}$

\begin{tabular}{|c|c|c|c|}
\hline Configurations & $T(\%)$ & $\lambda(\mathrm{nm})$ & Ref. \\
\hline $\begin{array}{c}\mathrm{K}_{x} \mathrm{WO}_{3} / \mathrm{KCF}_{3} \mathrm{SO}_{3} \\
\text { in } \mathrm{PEO}-\mathrm{PU} / \mathrm{PB}\end{array}$ & $14 \rightleftharpoons 56$ & 633 & [5-7] \\
\hline $\begin{array}{c}\mathrm{H}_{x} \mathrm{WO}_{3} / \mathrm{H}_{3} \mathrm{PO}_{4} \\
-\mathrm{KH}_{2} \mathrm{PO}_{4} \text { in } \\
\mathrm{PVA} / \mathrm{PB}\end{array}$ & $12 \rightleftharpoons 52$ & 690 & [8] \\
\hline $\begin{array}{l}\mathrm{Li}_{x} \mathrm{WO}_{3} / \mathrm{Li}^{+} \\
\quad-\mathrm{OMPE} / \mathrm{PB}\end{array}$ & $32 \rightleftharpoons 63$ & 790 & [9] \\
\hline $\begin{array}{r}\mathrm{Li}_{x} \mathrm{WO}_{3} / \mathrm{LiCF}_{3} \mathrm{SO}_{3} \\
\text { in } \mathrm{PAA}-\mathrm{PEO} / \mathrm{PB}\end{array}$ & & & [10] \\
\hline $\begin{array}{l}\mathrm{Li}_{x} \mathrm{WO}_{3} / \mathrm{LiClO}_{4} \text { in } \\
\quad \mathrm{PC} / \mathrm{PB}\end{array}$ & $10 \rightleftharpoons 60$ & Vis & [11-13] \\
\hline $\begin{array}{c}\mathrm{Li}_{x} \mathrm{WO}_{3} / \mathrm{LiClO}_{4} \text { in } \\
\mathrm{PC}+\mathrm{H}_{2} \mathrm{O} / \mathrm{PB}\end{array}$ & $\begin{array}{l}5-10 \rightleftharpoons 50 \\
-70\end{array}$ & Vis & {$[14,15]$} \\
\hline $\begin{array}{l}\mathrm{H}_{x} \mathrm{WO}_{3} / \text { Poly } \\
-\mathrm{AMPS}^{\mathrm{b}} / \mathrm{PB}\end{array}$ & $3 \rightleftharpoons 55$ & 550 & [16] \\
\hline $\begin{array}{l}\mathrm{H}_{x} \mathrm{WO}_{3} / \mathrm{P}(\mathrm{VSA}-\mathrm{VP}) \\
\quad / \mathrm{PB}\end{array}$ & $\begin{array}{l}3-6 \rightleftharpoons 62 \\
-72\end{array}$ & 550 & [17] \\
\hline $\begin{array}{l}\mathrm{H}_{x} \mathrm{WO}_{3} / \mathrm{P}(\mathrm{VSA}-\mathrm{VP}) \\
\quad / \mathrm{PB}\end{array}$ & $\begin{array}{l}4-13 \rightleftharpoons 43 \\
-70\end{array}$ & 550 & This work \\
\hline
\end{tabular}

${ }^{\mathrm{a}}(\mathrm{OMPE}=$ oxymethylene poly(oxyethylene); PAA = poly(acrylic acid); $\mathrm{PC}=$ propylene carbonate; $\mathrm{PEO}=$ poly(ethylene oxide); poly-AMPS = poly(2-acrylamido-2-methylpropane sulfonic acid); $\mathrm{PU}=$ polyurethane; $\mathrm{PVA}=$ poly (vinyl alcohol); $\mathrm{P}(\mathrm{VSA}-\mathrm{VP})=$ copolymer of vinylsulfonic acid and 1-vinyl-2pyrrolidinone; $\mathrm{VP}=1$-vinyl-2-pyrrolidinone; VSA $=$ vinylsulfonic acid)

${ }^{\mathrm{b}}$ AMPS is a registered trademark of Lubrizol Corporation.

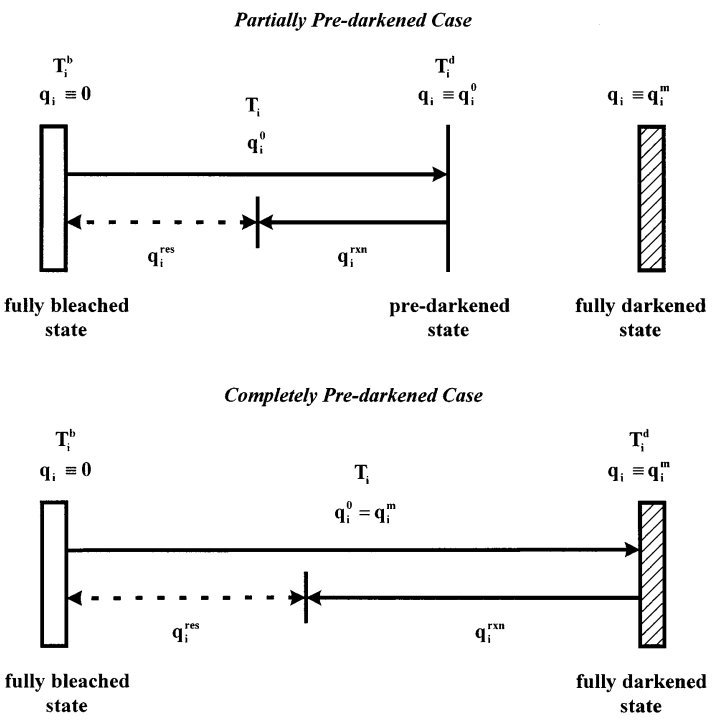

Fig. 1. Schematic representation describing the electrode's charge capacity in partially pre-darkened and completely predarkened conditions.

In this paper, the cell configuration of $\mathrm{H}_{x} \mathrm{WO}_{3} / \mathrm{H}^{+}$$\mathrm{SPE} / \mathrm{PB}$ is fabricated in which the $\mathrm{H}^{+}$-SPE is based on the copolymer of sodium vinylsulfonic acid ( $\mathrm{Na}^{+}$-VSA) and 1-vinyl-2-pyrrolidinone (VP) [18-20]. This class of copolymer electrolytes, when synthesized with an appropriate molar ratio of comonomer, is stable at temperatures as high as $90^{\circ} \mathrm{C}$, continuously for over a month [19].

\section{Model development}

In this section, the transmittance of a complementary ECD will be related to the electrochemical and optical properties of each coated electrochromic layer (EC layer). In the following derivation, we will present transmittance functions for the current system, $\mathrm{H}_{x} \mathrm{WO}_{3} / \mathrm{H}^{+}-\mathrm{SPE} / \mathrm{PB}$. However, it is apparent that the use of the equation is valid for all complementary ECDs.

\subsection{Conservation of charge}

It is a common practice that EC films have to be pre-colored before assembling into a complementary ECD. Fig. 1 is a schematic representation describing the electrode's charge capacity in partially pre-darkened and completely pre-darkened conditions. The conservation of charge on the $i$ th EC layer gives

$q_{i}^{\mathrm{res}}=q_{i}^{0}-q_{i}^{\mathrm{rxn}}$ 
where $q_{i}^{0}, q_{i}^{\mathrm{rxn}}$, and $q_{i}^{\mathrm{res}}$ represent the initial, reacted, and residual charge capacity of the $i$ th EC layer, respectively. Therefore, Eq. (3) can be put into the following form

$\eta_{i}(\lambda) \equiv\left[\frac{\Delta \mathrm{OD}_{i}(\lambda)}{q_{i}^{0}}\right]=\left[\frac{\log \left(T_{i}^{\mathrm{b}} / T_{i}^{\mathrm{d}}\right)}{q_{i}^{0}}\right]=\left[\frac{\log \left(T_{i}^{\mathrm{b}} / T_{i}\right)}{q_{i}^{\mathrm{res}}}\right]$

or

$T_{i}=T_{i}^{\mathrm{b}} \exp \left[-\eta_{i}^{\prime}\left(q_{i}^{0}-q_{i}^{\mathrm{rxn}}\right)\right]$

where

$\eta_{i}^{\prime}=2.303 \eta_{i}$

The transmittance of the $i$ th EC layer in the bleached state, $T_{i}^{\mathrm{b}}$, can be expressed as

$T_{i}^{\mathrm{b}}=\exp \left(-\alpha_{i} \delta_{i}\right)$

where $\alpha_{i}$ and $\delta_{i}$ represent the attenuation coefficient and the film thickness of the $i$ th EC layer, respectively. Since the maximum charge capacity of the $i$ th EC film, $q_{i}^{\mathrm{m}}$, is proportional to its thickness, $\delta_{i}$, i.e.

$q_{i}^{\mathrm{m}}=k_{i} \delta_{i}$

where $k_{i}$ is the proportionality constant, Eq. (9) becomes

$T_{i}^{\mathrm{b}}=\exp \left(-\alpha_{i}^{\prime} q_{i}^{\mathrm{m}}\right)$

where

$\alpha_{i}^{\prime}=\alpha_{i} / k_{i}$

The transmittance of the $i$ th EC layer can be related to its physical properties and its residual charge capacity according to

$T_{i}\left(q_{i}^{\mathrm{m}}, q_{i}^{\mathrm{res}}\right)=\exp \left(-\alpha_{i}^{\prime} q_{i}^{\mathrm{m}}\right) \exp \left[-\eta_{i}^{\prime}\left(q_{i}^{0}-q_{i}^{\mathrm{rxn}}\right)\right]$

\subsection{Transmittance functions}

Taking the complementary $\mathrm{H}_{x} \mathrm{WO}_{3} / \mathrm{H}^{+}-\mathrm{SPE} / \mathrm{PB}$ system as an example, the overall transmittance of the device is the multipliers of the transmittance of each component. That is, the transmittance of the ECD can be formulated by the following expression

$T_{\mathrm{ECD}}=\phi T_{\mathrm{p}} T_{\mathrm{w}}$

where $T_{\mathrm{ECD}}, T_{\mathrm{p}}$, and $T_{\mathrm{w}}$ represent the transmittances of $\mathrm{ECD}, \mathrm{PB}$, and $\mathrm{WO}_{3}$, respectively. $\phi$ is the combined transmittance accounting for the presence of both transparent conducting substrate and SPE. From Eq. (13), the transmittances of electrochromic Prussian blue and tungsten oxide can be written as

$T_{\mathrm{p}}=\exp \left(-\alpha_{\mathrm{p}}^{\prime} q_{\mathrm{p}}^{\mathrm{m}}\right) \exp \left[-\eta_{\mathrm{p}}^{\prime}\left(q_{\mathrm{p}}^{0}-q^{\mathrm{rxn}}\right)\right]$

and

$T_{\mathrm{w}}=\exp \left(-\alpha_{\mathrm{w}}^{\prime} q_{\mathrm{w}}^{\mathrm{m}}\right) \exp \left[-\eta_{\mathrm{w}}^{\prime}\left(q_{\mathrm{w}}^{0}-q^{\mathrm{rxn}}\right)\right]$
Notice that

$q^{\mathrm{rxn}}=q_{\mathrm{p}}^{\mathrm{rxn}}=q_{\mathrm{w}}^{\mathrm{rxn}}$

Assuming that both the conducting substrate and SPE are transparent $(\phi=1)$, the transmittance of the ECD is

$T_{\mathrm{ECD}}=T_{\mathrm{ECD}}^{\mathrm{m}} \exp \left[-\eta_{\mathrm{p}}^{\prime}\left(q_{\mathrm{p}}^{0}-q^{\mathrm{rxn}}\right)-\eta_{\mathrm{w}}^{\prime}\left(q_{\mathrm{w}}^{0}-q^{\mathrm{rxn}}\right)\right]$

where

$T_{\mathrm{ECD}}^{\mathrm{m}}=\exp \left[-\left(\alpha_{\mathrm{p}}^{\prime} q_{\mathrm{p}}^{\mathrm{m}}+\alpha_{\mathrm{w}}^{\prime} q_{\mathrm{w}}^{\mathrm{m}}\right)\right]$

\subsection{Charge capacity ratio and limiting electrode}

Let us define the charge capacity ratio, $R$, as the initial charge capacity of $\mathrm{WO}_{3}$ to that of $\mathrm{PB}$, i.e.

$R=q_{\mathrm{w}}^{0} / q_{\mathrm{p}}^{0}$

On the basis of our previous study on complementary ECDs [21,22], it was found that the electrode with a lower charge capacity would determine the amount of charge consumed per unit area when switching occurs. The electrode with a lower charge capacity is usually called the limiting electrode. In fact, the concept of the limiting electrode can be understood both experimentally [21] and theoretically [22] by comparing the cyclic voltammetries for cells made with various charge capacity ratios. The concept of the limiting electrode, indeed, is expected by considering the general charge limitation model in a complementary electrochromic system as proposed by Rauh and Cogan [23]. Therefore, the charge consumed per unit area in a complementary ECD, $q^{\mathrm{rxn}}$, can be expressed by the following equation

$q^{\mathrm{rxn}}=\operatorname{Min}\left(q_{\mathrm{p}}^{0}, q_{\mathrm{w}}^{0}\right)$

\subsection{Transmittance window}

In the case when $0 \leq R \leq 1, \quad\left(q_{\mathrm{w}}^{0} \leq q_{\mathrm{p}}^{0}\right)$, the final bleached state and the initial darkened state transmittances, $T_{\mathrm{ECD}}^{\mathrm{b}}$ and $T_{\mathrm{ECD}}^{\mathrm{d}}$, of the device can be obtained from Eq. (18) by setting $q^{\mathrm{rxn}}=q_{\mathrm{w}}^{0}$ and $q^{\mathrm{rxn}}=0$, respectively. That is

$T_{\mathrm{ECD}}^{\mathrm{b}}=T_{\mathrm{ECD}}^{\mathrm{m}} \exp \left[-\eta_{\mathrm{p}}^{\prime} q_{\mathrm{p}}^{0}(1-R)\right]$

and

$T_{\mathrm{ECD}}^{\mathrm{d}}=T_{\mathrm{ECD}}^{\mathrm{m}} \exp \left[-q_{\mathrm{p}}^{0}\left(\eta_{\mathrm{p}}^{\prime}+\eta_{\mathrm{w}}^{\prime} R\right)\right]$

The transmittance window for $0 \leq R \leq 1, \Delta T_{\mathrm{ECD}}(0 \leq$ $R \leq 1$ ), is obtained by subtracting Eq. (23) from Eq. (22)

$$
\begin{aligned}
& \Delta T_{\mathrm{ECD}}(0 \leq R \leq 1) \\
&= T_{\mathrm{ECD}}^{\mathrm{m}}\left[\exp \left[-\eta_{\mathrm{p}}^{\prime} q_{\mathrm{p}}^{0}(1-R)\right]\right. \\
&\left.-\exp \left[-q_{\mathrm{p}}^{0}\left(\eta_{\mathrm{p}}^{\prime}+\eta_{\mathrm{w}}^{\prime} R\right)\right]\right]
\end{aligned}
$$


Similarly, when $R \geq 1,\left(q_{\mathrm{w}}^{0} \geq q_{\mathrm{p}}^{0}\right)$, the final bleached state and the initial darkened state transmittances, $T_{\mathrm{ECD}}^{\mathrm{b}}$ and $T_{\mathrm{ECD}}^{\mathrm{d}}$, of the device can be obtained from Eq. (18) by setting $q^{\mathrm{rxn}}=q_{\mathrm{p}}^{0}$ and $q^{\mathrm{rxn}}=0$, respectively. That is

$T_{\mathrm{ECD}}^{\mathrm{b}}=T_{\mathrm{ECD}}^{\mathrm{m}} \exp \left[-\eta_{\mathrm{w}}^{\prime} q_{\mathrm{p}}^{0}(R-1)\right]$

and as in Eq. (23) The transmittance window for $R \geq 1$, $\Delta T_{\mathrm{ECD}}(R \geq 1)$, is obtained by subtracting Eq. (23) from Eq. (25)

$$
\begin{aligned}
& \Delta T_{\mathrm{ECD}}(R \geq 1) \\
&= T_{\mathrm{ECD}}^{\mathrm{m}}\left[\exp \left[-\eta_{\mathrm{w}}^{\prime} q_{\mathrm{p}}^{0}(R-1)\right]\right. \\
&\left.-\exp \left[-q_{\mathrm{p}}^{0}\left(\eta_{\mathrm{p}}^{\prime}+\eta_{\mathrm{w}}^{\prime} R\right)\right]\right]
\end{aligned}
$$

\section{Experimental}

\section{1. $\mathrm{WO}_{3}$ working electrode}

The experimental procedures for the preparation of $\mathrm{WO}_{3}$ have been described elsewhere [24]. $\mathrm{WO}_{3}$ was vacuum-deposited on fluorine-doped tin oxide (FTO)-coated glass substrates. The sheet resistance of FTO-coated glass substrates was measured by the four-point probe method and was $10 \Omega / \square$. Conductive copper bus bars were applied on all four sides of the FTO-coated substrate. FTO-coated glass substrates, with size $13.0 \times 17.5 \times 0.23 \mathrm{~cm}^{3}$, were precleaned ultrasonically in an aqueous cleaner solution reported previously [24,25]. Tungsten oxide films prepared in this way had a thickness of $370 \pm 50 \mathrm{~nm}$. X-ray diffraction analysis, with a Rigaku diffractometer (Model D-2655) using monochromatized $\mathrm{Cu} \mathrm{K} \mathrm{K}_{\alpha}$ incident radiation, showed all the films to be lacking crystallinity.

\subsection{PB counter-electrode}

The sacrificial anode method, which is based on the cathodic electrodeposition mentioned by Ellis et al. [26] for PB deposition, was modified and used in this work. The modified sacrificial method for PB deposition was described elsewhere [27]. The solution contained $5 \mathrm{mM}$ of $\mathrm{FeCl}_{3} \cdot 6 \mathrm{H}_{2} \mathrm{O}$ and $5 \mathrm{mM}$ of $\mathrm{K}_{3} \mathrm{Fe}(\mathrm{CN})_{6}$. It takes about $30 \mathrm{~min}$ to deposit the desired amount of PB on FTO-coated glass. The thickness of the PB film was controlled at $475 \pm 25 \mathrm{~nm}$ by counting the passed charge, which is proportional to the amount of PB deposited. In all cases, the charge capacity for the deposition was controlled at $13.2 \mathrm{mC} /$ $\mathrm{cm}^{2}$. X-ray diffraction analysis, with a Rigaku diffractometer (Model D-2655), using monochromatized $\mathrm{Cu}$ $\mathrm{K}_{\alpha}$ incident radiation, showed all the films to be crystalline.

\subsection{Solid polymer electrolyte}

The transparent electrolyte is the copolymer based on the copolymerization of $\mathrm{Na}^{+}$-VSA and VP [18]. The sodium form of this copolymer is exchanged to the acid form for use as the electrolyte in electrochromic devices. $\mathrm{Na}^{+}$-VSA/VP copolymerization is intentionally done with a slightly enriched VP than desired: 1.6:1 $\mathrm{Na}^{+}$VSA/VP to obtain $2: 1$ poly $\left(\mathrm{Na}^{+}-\mathrm{VSA} / \mathrm{VP}\right)$ copolymer, for example. The experimental details for the preparation of the copolymer were described elsewhere [19].

\subsection{Cell assembly}

Before assembling the cells, the $\mathrm{WO}_{3}$ electrode was pre-charged with protons. A constant current density of $0.11 \mathrm{~mA} / \mathrm{cm}^{2}$ was used in cathodizing the tungsten oxide electrode. It takes about 4 min to get the pre-determined amount of protons, which will be described in Section 4, into the tungsten oxide thin film. The tungsten bronze, $\mathrm{H}_{x} \mathrm{WO}_{3}$, was then rinsed with distilled water and dried under $\mathrm{N}_{2}$. The polymer electrolyte was flow-coated on both electrodes. Conditioning was done in a room with a controlled relative humidity of $35 \%$ at $23^{\circ} \mathrm{C}$. Cells were intimately laminated together with $\mathrm{H}_{x} \mathrm{WO}_{3}$ as the working electrode and $\mathrm{PB}$ as the counter-electrode. The lamination was carried out in an autoclave at a pressure of $1.03 \times 10^{6} \mathrm{~N} / \mathrm{m}^{2}$ and a tem-

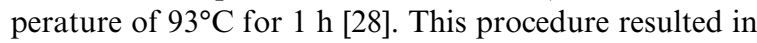
an averaged thickness of $100 \mu \mathrm{m}$ for the copolymer electrolyte, as measured by a micrometer across the samples. After autoclaving, each cell was sealed around all four edges with butyl rubber. The electroactive areas of the ECD was $10.2 \times 15.2 \mathrm{~cm}^{2}$.

\subsection{Electrochemical runs}

The coloration and bleaching of cells were carried out by applying a constant dc voltage (Keithley voltage/current source, Model 228A). The transmittance, current and drift of the cell voltage were recorded. The change in optical transmittance during coloration and bleaching was measured at $550 \mathrm{~nm}$ with a Cary-14 spectrophotometer. Transmittance data were taken at or near the center of each cell, depending on the size of the sample.

\section{Results and discussion}

\subsection{Electrochromic performance}

Five ECDs, each with different charge capacity ratios, were made. $\mathrm{WO}_{3}$ electrodes (active area $=10.2 \times$ $15.2 \mathrm{~cm}^{2}$ ) were pre-charged in copolymer solution in order to optimize the pre-charging conditions, to match 
Table 2

Electrochromic samples made with different $R$ values switched at +1.2 and $-0.6 \mathrm{~V}$

\begin{tabular}{lllllll}
\hline Samples & $R$ & $T_{550}(\%)$ & $\Delta T(\%)$ & $\Delta \mathrm{OD}$ & $q^{\mathrm{rxn}}\left(\mathrm{mC} / \mathrm{cm}^{2}\right)$ & $\eta\left(\mathrm{cm}^{2} / \mathrm{C}\right)$ \\
\hline S-1 & 0.66 & $12.0 \rightleftharpoons 53.0$ & 41.0 & 0.65 & 11.36 & 56.8 \\
S-2 & 0.82 & $13.0 \rightleftharpoons 62.5$ & 49.5 & 0.68 & 12.72 & 53.6 \\
S-3 & 1.15 & $6.6 \rightleftharpoons 70.2$ & 63.6 & 1.03 & 20.00 & 51.3 \\
S-4 & 1.32 & $5.2 \rightleftharpoons 57.4$ & 52.2 & 1.04 & 19.03 & 54.8 \\
S-5 & 1.48 & $3.9 \rightleftharpoons 43.0$ & 39.1 & 1.04 & 17.79 & 58.6 \\
\hline
\end{tabular}

the charge capacity of the PB electrode of the same size. The $\mathrm{WO}_{3}$ electrodes were pre-charged at different proton levels just before the cells were put together. The charge capacity of the $\mathrm{H}_{x} \mathrm{WO}_{3}$, denoted by $q_{\mathrm{w}}^{0}$, is the amount of charge injected per unit area of electrode. The charge capacity of the $\mathrm{PB}$, denoted by $q_{\mathrm{p}}^{0}$, is the charge consumption per unit electrode area in reducing $\mathrm{PB}$ to Prussian white $\left(\mathrm{M}_{4} \mathrm{Fe}_{4}^{\mathrm{II}}\left[\mathrm{Fe}^{\mathrm{II}}(\mathrm{CN})_{6}\right]_{3}, \mathrm{PW}\right)$. The value of $q_{\mathrm{p}}^{0}$ was determined experimentally by switching the PB electrode in the copolymer solution cathodically at $-0.6 \mathrm{~V}$ against a $\mathrm{Pt}$ electrode. The value of $q_{\mathrm{p}}^{0}$ is $21.61 \mathrm{mC} / \mathrm{cm}^{2}$ for a $\mathrm{PB}$ electrode with an active area of $155.0 \mathrm{~cm}^{2}$. The pre-charging capacities on the tungsten oxide electrode were varied from 14.22, 17.78, 24.89, 28.44 , and $32.00 \mathrm{mC} / \mathrm{cm}^{2}$, corresponding to the charge capacities ratio of $0.66,0.82,1.15,1.32$, and 1.48 , respectively. Table 2 summarizes the switching results when the samples were freshly darkened at $+1.2 \mathrm{~V}$ and bleached at $-0.6 \mathrm{~V}$. The voltage is the potential difference between the $\mathrm{PB}$ electrode and the tungsten oxide electrode $\left(\mathrm{PB}\right.$ vs. $\left.\mathrm{WO}_{3}\right)$. These voltages are within the electrochemically safe voltage limits, which were pre-determined from the cyclic voltammetry of the cell with the current configuration of $\mathrm{H}_{x} \mathrm{WO}_{3} / \mathrm{P}(\mathrm{VSA}-\mathrm{VP}) / \mathrm{PB}$.

The transmittance (at $550 \mathrm{~nm}$ ) ranges, recorded at the geometric center during cyclic potentiostatic switching for five samples, are listed in Table 2. The average coloration efficiency for five ECDs is calculated to be $55.0 \mathrm{~cm}^{2} / \mathrm{C}$ at $550 \mathrm{~nm}$.

\subsection{Charge consumption}

Fig. 2 shows the charge consumed per unit area as a function of the charge capacity ratio. The experimental data are shown by the diamond points while the model prediction is shown by the solid line based on the measured value of $q_{\mathrm{p}}^{0}=21.61 \mathrm{mC} / \mathrm{cm}^{2}$. The dotted line is the best fit to the model with a value of $q^{\text {calc }}=$ $17.91 \mathrm{mC} / \mathrm{cm}^{2}$, which is $17 \%$ smaller than the measured value. The discrepancy in $q^{\mathrm{rxn}}$ is due to the partial oxidation of the $\mathrm{H}_{x} \mathrm{WO}_{3}$ electrode, in the presence of $\mathrm{O}_{2}$ in the electrolyte [17], through Eq. (27)

$\mathrm{H}_{x} \mathrm{WO}_{3} \cdot m \mathrm{H}_{2} \mathrm{O}+\frac{x}{4} \mathrm{O}_{2} \rightarrow \mathrm{WO}_{3} \cdot\left(m+\frac{x}{2}\right) \mathrm{H}_{2} \mathrm{O}$.

\subsection{Transmittance vs. charge capacity ratio}

The data points in Fig. 3 indicate the bleached and darkened state transmittances measured at $550 \mathrm{~nm}$, which are designated by $T_{\mathrm{ECD}}^{\mathrm{b}}$ and $T_{\mathrm{ECD}}^{\mathrm{d}}$, respectively, against the ratio of charge capacity, $R$, of the $\mathrm{H}_{x} \mathrm{WO}_{3}$ to that of the $\mathrm{PB}, R \equiv q_{\mathrm{w}}^{0} / q_{\mathrm{p}}^{0}$. Both the darkened and the bleached state transmittances were fitted very well with the model, as revealed by the modeling curves by choosing $T_{\mathrm{ECD}}^{\mathrm{m}}=0.8$ and $\eta_{\mathrm{p}}^{\prime}=\eta_{\mathrm{w}}^{\prime}$.

The experimental data shown in Fig. 4 are the transmittance window measured at $550 \mathrm{~nm}, \Delta T_{\mathrm{ECD}} \equiv$ $T_{\mathrm{ECD}}^{\mathrm{b}}-T_{\mathrm{ECD}}^{\mathrm{d}}$, against the ratio of charge capacity, $R$. It was interesting to find experimentally that the closer the ratio of two charge capacities to unity $(R \rightarrow 1.0)$, the wider the transmittance window or attenuation. In fact, the theoretical model predicts the experimental results very well, as shown by the curve in Fig. 4.

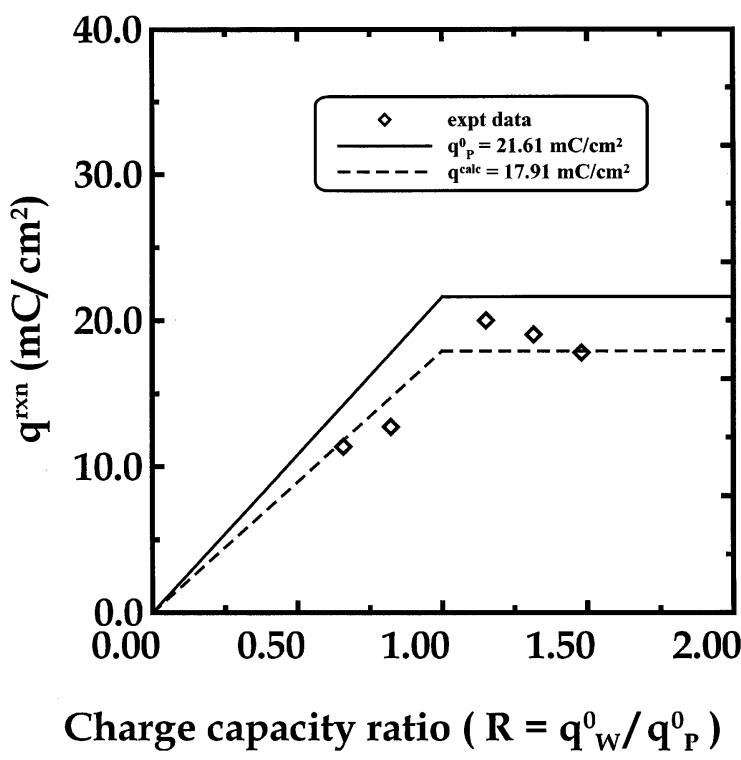

Fig. 2. The charge consumed per unit area as a function of the charge capacity ratio. The experimental data are shown by the diamond points while the model prediction is shown by the curve. 


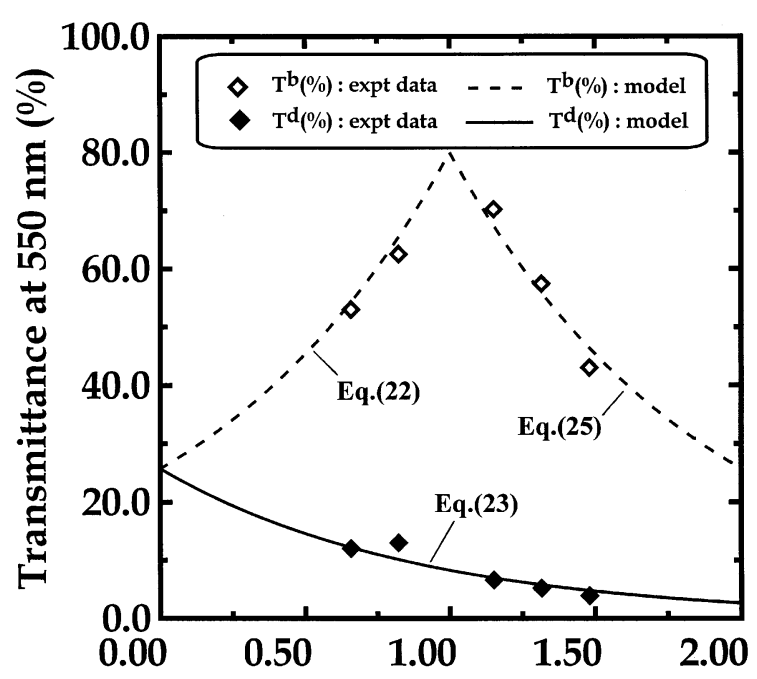

\section{Charge capacity ratio $\left(R=q_{w}^{0} / q_{P}^{0}\right)$}

Fig. 3. Bleached and darkened state transmittances at $550 \mathrm{~nm}$ as a function of the charge capacity ratio. The experimental data are shown by the diamond points while the model predictions are shown by the curves with $T_{\mathrm{ECD}}^{\mathrm{m}}=0.8$ and $\eta_{\mathrm{p}}^{\prime}=\eta_{\mathrm{w}}^{\prime}$. The active area of the ECD is $155.0 \mathrm{~cm}^{2}$.

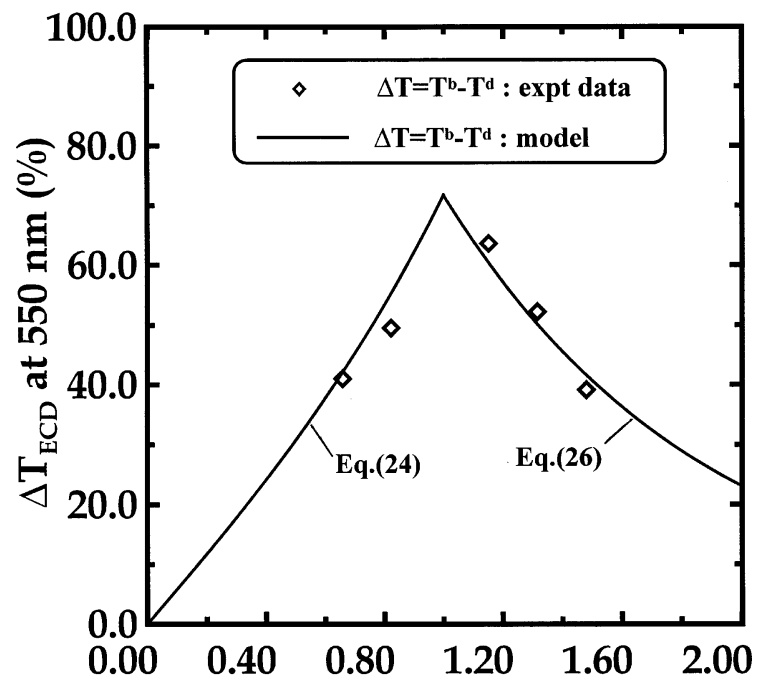

\section{Charge capacity ratio $\left(R=q_{w}^{0} / q_{P}^{0}\right)$}

Fig. 4. Transmittance window at $550 \mathrm{~nm}$ as a function of the charge capacity ratio. The experimental data are shown by the diamond points while the model prediction is shown by the curve. The active area of the ECD is $155.0 \mathrm{~cm}^{2}$.

\section{Conclusions}

This study deals with balancing the electrode capacities in a complementary, solid-state electrochromic device so as to optimize its optical attenuation. This work outlines the combined electrochemical and optical design equations for complementary ECDs with application to the solid-state electrochromic configuration of $\mathrm{H}_{x} \mathrm{WO}_{3} / \mathrm{H}^{+}-\mathrm{SPE} / \mathrm{PB}$. The present research provides a simple engineering guideline for designing the complementary ECDs. It will also help in better understanding the key factors that govern the performance of complementary ECDs. The main conclusions from this study are:

1. The concept of the limiting electrode is verified experimentally for complementary ECDs by observing $q^{\mathrm{rxn}}=\operatorname{Min}\left(q_{\mathrm{p}}^{0}, q_{\mathrm{w}}^{0}\right)$.

2. The matching of two charge capacities in a complementary ECD was confirmed experimentally by showing that the closer the ratio of the two charge capacities to unity $(R \rightarrow 1.0)$, the wider the transmittance window.

3. By combining the electrochemical and optical properties of these two electrodes, design equations suitable for complementary ECDs are derived. These equations are fitted very well with our experimental data.

4. The principle of optimal design in obtaining the maximum optical attenuation is to equalize the charge capacity on both the EC layers.

\section{Acknowledgements}

This work was sponsored by the National Research Council of the Republic of China under contract numbers NSC 87-2214-E002-034 and NSC 89-2214-E002017. The experimental work was partially done while one of the authors (K.-C.H.) worked at the Glass Technology Center, PPG Industries, Inc., Pittsburgh, PA. We are indebted to T.G. Rukavina for guidance in the preparation of copolymer electrolytes. We would like to thank J.B. McCandless and J.B. Slobodnik for sample preparation.

\section{References}

[1] C.G. Granqvist, Handbook of Inorganic Electrochromic Materials, Elsevier, Amsterdam, 1995.

[2] K. Itaya, I. Uchida, V.D. Neff, Acc. Chem. Res. 19 (1986) 162

[3] K. Itaya, T. Ataka, S. Toshima, J. Am. Chem. Soc. 104 (1982) 4767.

[4] Y. Yano, N. Kinugasa, H. Yoshida, K. Fujino, H. Kawahara, in: M.K. Carpenter, D.A. Corrigan (Eds.), Electrochromic Materials, PV 90-2, 1990, p. 125, The Electrochemical Society Softbound Proceedings Series, Pennington, NJ.

[5] H. Tada, Y. Bito, K. Fujino, H. Kawahara, Sol. Energy Mater. 16 (1987) 509. 
[6] H. Tada, Y. Bito, K. Fujino, H. Kawahara, in: L.T. Romankiw, T. Osaka (Eds.), Electrochemical Technology in Electronics, PV 88-23, 1987, p. 325, The Electrochemical Society Softbound Proceedings Series, Pennington, NJ.

[7] H. Tada, H. Nagayama, H. Kawahara, US Patent No. 4,726,664, 1988.

[8] M.A. Habib, S.P. Maheswari, M.K. Carpenter, J. Appl. Electrochem. 21 (1991) 203.

[9] M.A. Habib, S.P. Maheswari, J. Electrochem. Soc. 139 (1992) 2155.

[10] N. Oyama, T. Ohsaka, M. Menda, H. Ohno, Denki Kagaku 57 (1989) 1172.

[11] T. Miyamoto, M. Ura, S. Kazama, T. Kase, Y. Maeda, US Patent No. 4,645,307, 1987.

[12] H. Inaba, K. Nakase, Y. Yanagida, H. Nishii, US Patent No. 4,773,741, 1988.

[13] M. Kawai, H. Miyagi, M. Ura, US Patent No. 4,801,195, 1989.

[14] T. Kase, M. Kawai, M. Ura, SAE Technical Paper Series, No. 861,362, 1986.

[15] T. Kase, T. Miyamoto, T. Yoshimoto, Y. Ohsawa, H. Inaba, K. Nakase, in: C.M. Lampert, C.G. Granqvist (Eds.), Large-Area Chromogenics: Materials and Devices for Transmittance Control, SPIE Optical Engineering Press, Bellingham, WA, 1990, p. 504.

[16] K.-C. Ho, T.G. Rukavina, C.B. Greenberg, J. Electrochem. Soc. 141 (1994) 2061.
[17] K.-C. Ho, Electrochim. Acta 44 (1999) 3227.

[18] A. Kutner, D.S. Breslow, J. Polym. Sci. 38 (1959) 274.

[19] T.G. Rukavina, in: K.-C. Ho, C.B. Greenberg, D.M. MacArthur (Eds.), Electrochromic Materials III, PV 96-24, 1997, p. 36, The Electrochemical Society Proceedings Series, Pennington, NJ.

[20] C.S. Harris, T.G. Rukavina, Electrochim. Acta 40 (1995) 2315.

[21] K.-C. Ho, L.-C. Chen, C.-C. Lee, in: C.M. Lampert (Ed.), Switchable Materials and Flat Panel Displays, SPIE Proceedings Series, 3788, 1999, p. 120.

[22] L.-C. Chen, K.-C. Ho, Electrochim. Acta 46 (2001) 2159 2166.

[23] R.D. Rauh, S.F. Cogan, J. Electrochem. Soc. 140 (1993) 378.

[24] K.-C. Ho, D.E. Singleton, C.B. Greenberg, J. Electrochem. Soc. 137 (1990) 3858.

[25] K.-C. Ho, J. Electrochem. Soc. 139 (1992) 1099.

[26] D. Ellis, M. Eckhoff, V.D. Neff, J. Phys. Chem. 85 (1981) 1225.

[27] K.-C. Ho, in: K.-C. Ho, D.M. MacArthur (Eds.), Electrochromic Materials II, PV 94-2, 1994, p. 170, The Electrochemical Society Proceedings Series, Pennington, NJ.

[28] C.B. Greenberg, T.G. Rukavina, D.E. Singleton, US Patent, 5,124,832, 1992. 